OPEN ACCESS

Edited by:

Jesus Arroyave,

Universidad del Norte,

Colombia, Colombia

Reviewed by:

M. Teresa Anguera,

University of Barcelona, Spain

Stephen Harper,

University of Portsmouth,

United Kingdom

*Correspondence:

María Inés Marino

maria.marino1@fiu.edu

Specialty section:

This article was submitted to

Health Communication,

a section of the journal

Frontiers in Communication

Received: 10 April 2020 Accepted: 22 September 2020

Published: 21 October 2020

Citation:

Marino MI, Adogba O and Tilli N (2020) Mental Health Interventions:

Reflections on a Radio Program as Alternative for Stigma Reduction and

Social Integration.

Front. Commun. 5:550912.

doi: $10.3389 /$ fcomm.2020.550912

\section{Mental Health Interventions: Reflections on a Radio Program as Alternative for Stigma Reduction and Social Integration}

\author{
Maria Inés Marino ${ }^{1 *}$, Oluwabusola Adogba ${ }^{1}$ and Nicolas Tilli $^{2}$ \\ 'Department of Communication, Florida International University, Miami, FL, United States, ${ }^{2}$ Department of Communication, \\ Universite Toulouse Capitol, Toulouse, France
}

Under the umbrella of Social Identity Theory and Goffman's notion of stigma, this paper reviews research on stigma in connection with social perceptions of individuals with mental health problems and the role of the media in building those perceptions. The study specifically examined three aspects: (1) social stigma of individuals with mental health problems; (2) media as an alternative intervention for individuals with mental health problems, and (3) alternative interventions for stigma reduction and social integration. Based on data collected via testimonies from an in-hospital radio show, from hospitalized patients with mental health problems, and from the audience, the study was designed to address the question of how mass media could act as an alternative mental health intervention to help reduce stigma and promote social integration.

Keywords: media, mental health, alternative, interventions, stigma (social), integration

In this study, researchers examined stigma with specific emphasis on perceptions of individuals with mental health problems and the role of the media in building those perceptions. Our focus comes from the need to address the question of how mass media could act as an alternative mental health intervention. Our specific goal is to help reduce stigma through social empathy toward individuals with mental health issues to promote integration and advance broader community goals.

Communication focuses on social interactions through which people generate and share meaning across contexts, cultures, media, and channels (Samovar et al., 2010). In the process of sharing and generating meaning, culture teaches us how to communicate with others, what to pay attention to, and how to interpret messages when we communicate (Knutson et al., 2003; Kreijns et al., 2003; Chen, 2012). Communication is essential to the process of culture, since the way we communicate and how we understand communication are intimately related and impacted by contextual and cultural factors (Hall, 1976; Jaldemark, 2008; Yang et al., 2010). A key factor in the process of communication is how we communicate ideas through the use of language in representations of "the Other." Through the use of language, we cultivate ideas, influence perception building, and empower notions of discrimination, stereotyping and stigma which contribute to the shaping of social identity of "the Other" (Smith, 2007). 
Researchers (Smith et al., 2019) have examined the exposure to stigma messages and have found that stigma messages lead to prejudice. As a result, media may hold great responsibility, especially in relation to stigmas associated with mental illnesses. The critique of media coverage indicates that news stories may result in devaluing and discriminating against those affected by a mental health condition (Smith et al., 2019). When stigma messages are communicated, specifically through media, they become social facts and collective norms which operate at various social levels and powerfully impact people's beliefs and actions (Rimal and Lapinski, 2015; Smith et al., 2019). Nevertheless, stigma messages evoke emotions, which generate possible negative reactions against the stigmatized group due to the fact that these members (individuals with mental health problems) are portrayed as dangerous, unproductive, and isolated. Likewise, this representation increases bonding among the non-stigmatized members (Lawler et al., 2000; Heath et al., 2001; Hoffner and Cohen, 2018; Smith et al., 2019) and differentiates from the stigmatized individuals through hostile and negative reactions. The members of the stigmatized groupin this case persons who suffer from mental health disordersare designated as a social group and are assigned a social label. Consequently, they are devalued, discredited, and shamed by "the majority," leading to adverse life consequences (Goffman, 1963). Furthermore, Goffman discusses how individuals with mental health problems might avoid socializing to conceal their condition to avoid marginalization, discredit, and losing of social opportunities (Goffman, 1963; Link and Phelan, 2006). At the same time, feedback on the representation of mental health individuals not only generates interpersonal dissociation from stigmatized people, but these social beliefs also detrimentally impact them at a public level, resulting in poor promotion of public policies, limited support and reduction of public funding for mental health care (Corrigan et al., 2004; Smith, 2007, 2011). Finally, and in addition, these key factors and negative outcomes have been found to be an obstacle to seeking treatment, due in part to the unwillingness of individuals to associate themselves with a stigmatized group (Kosyluk et al., 2016; Hoffner and Cohen, 2018).

\section{SOCIAL IDENTITY THEORY}

Social identity theory was introduced by Tajfel (1978), and furthered developed by Tajfel et al. (1979) and Tajfel and Turner (1986). This theory proposes that the social identity of an individual is shaped through group identification, and the identification with a group becomes the source of pride and self-esteem which the individual uses to build a positive selfconcept. One strategy to maintain and protect this positive selfimage and self-identity is that members who pertain to the same group are evaluated in a more positive manner, as "in-group members protect their own self-esteem by showing favoritism and leniency toward other in-group members, despite their transactions" (Hawley et al., 2014, p. 61). Another strategy to maintain and protect the positive self-image and self-identity is that outsiders are stereotyped and discriminated against (Tajfel,
1978; Tajfel et al., 1979) through social categorization (Tajfel, 1982; Hogg and Terry, 2000; Hawley et al., 2014).

When categorizing, in-group members (us) identify with the group identity to distinguish themselves from outsiders (them) through intergroup comparisons and stereotyping. In other words, "if belonging to a certain group makes individuals feel good about themselves, maintaining affiliation with that group and preserving its positive evaluation compared to other groups will be very important to them" (Shinnar, 2008, p. 554). For example, research by Smith (2007), shows that if people stigmatize others in the absence of stigma, they may be punished by their community for dehumanizing an individual. However, if a stigma exists and there is no stigmatization by members of the non-stigmatized group, then they are considered betrayers of their group.

\section{GOFFMAN'S NOTION OF STIGMA}

Social Identity Theory is consistent with Goffman's (1963) notion of stigma. Following Goffman's (1963) studies, stigma is articulated through a social process and is an ascription that is deeply discrediting. This social process is enacted and constructed through social interactions that require language. Consequently, the particular social and cultural rules at a given point guide individual perceptions, shape expectations, and norms of the "normal and the different" (Pescosolido and Martin, 2015; Clair et al., 2016). Based on unrealistic and uninformed social and cultural expectations, stigma separates individuals, in this case individuals with mental health disorders, and the rest of the society, "marking" the stigmatized persons in detrimental ways through stereotypes, prejudice, and complete exclusion from "normal" social activities. In other words, the stigmatized individuals, based on their mental health status, are viewed and perceived as "out-of-normal-society." For example, individuals with mental health problems have historically been the target of negative social perceptions, resulting in rejection and criticism generated by the stigmatization (Chernomas et al., 2000; Hinshaw and Cicchetti, 2000).

In sum, Social Identity Theory demonstrates a bias toward the familiar, or the in-group members (or society in general), while expressing disapproval for the out-group individuals (stigmatized individuals). In-group/out-group borders are determined through cultural identifiers such as social inclusion and integration, and are associated with determinants (representation through language, media, social status, etc.) that represent significant ways in which our culture views individuals with mental health disorders. The stigmatization of individuals who suffer from mental health disorders or problems increases the distance between them and the rest of society, due to the negative social representations. This distance contributes to increasingly negative social perceptions toward the stigmatized group and increases the desire to avoid individuals who hold stigmatized statuses because they are perceived as a social threat (Pescosolido et al., 2008). The isolation of individuals with mental health disorders only feeds back into the notion that a person with mental health issues cannot be functional to society. 
Goffman (1961) coined the term "total institution," referring to the lives of individuals with mental health disorders living in institutional settings or asylums. Goffman described the mental institutions as similar to prisons where patients received custodial care with limited access to the outside world. In these types of institutions, patients follow a strict and dictated institutional routine, are isolated from the wider society for an extensive period of time and are subjected to restriction of freedom, suffer from stigma, and have their normal social roles taken away, which then leads to the loss of their usual identify (Chow and Priebe, 2013). Since 1950, the conceptualization of institutionalization has been changing toward the concept of "de-institutionalization."

Researchers (Farnese and Langher, 2010) explain deinstitutionalization of mental health as a process that consists partly of the discharge of patients from the large psychiatric hospitals to the alternative community services that provide necessary medical and psycho-social assistance. However, there has been an ongoing critical and polarized debate among health care professionals, government, and advocates for the mentally ill about the availability and feasibility of de-institutionalization of mental health.

As one of the proposed solutions, some studies and experts (Novella, 2010; Prins, 2011) have talked about deinstitutionalization through a reform that promotes the improvement of community-based program that could fulfill patients' needs and care, as well as the quality of life available to the individuals with mental health issues from the outside community. Part of this reform comprises activities and therapies that motivate interactive relationships between people with mental health disease and their potential environment in which multidisciplinary staff (such as psychologists, psychiatrists, and social workers) deal with patient treatment through various psychological therapies such as via the connection to the outside community (Farnese and Langher, 2010). In a similar manner, researchers (Farnese and Langher, 2010; Chow and Priebe, 2013) assert that new alternative services within the community can be seen as part of de-institutionalization.

\section{ROLE OF MEDIA IN BUILDING REPRESENTATIONS OF INDIVIDUALS WITH MENTAL HEALTH DISORDERS}

Stigma and biases are socially constructed through everyday discourse perpetuated through the context of communication, which includes the media (Lowstedt and Mboti, 2017; Sui and Paul, 2017). Research shows that media influences people's perceptions of each other (Gorodzeisky and Semyonov, 2017). These perceptions lead to various presumptions, which could be more positive or negative attributions based on the familiarity or differences with "the Other" (Weaver, 2007; Zebrowitz et al., 2007).

As the literature demonstrates, there is a perceived connection between individuals with mental health problems and certain specific characteristics and simplified and standardized descriptions. These perceptions stigmatize the individuals as a group that have been diffused within a larger community (Smith, 2007). Mass media has a great deal of responsibility for perpetuating these negative perceptions toward persons with mental health disorders (Coverdale et al., 2002; Muñoz et al., 2011). These individuals are commonly inaccurately represented as being incompetent and incapable, dangerous, and violent, people who violate or may violate social norms, and who have no hope of being effectively treated (Cutcliffe and Hannigan, 2001; Cuenca, 2003; Huang and Priebe, 2003; Crespo et al., 2008; Smith et al., 2019). For instance, researchers (Muñoz et al., 2011) have analyzed the representation of individuals with mental health issues in media (radio, television, and print media) and they found that these individuals are portrayed through abusive and improper terminology, content which is stigmatizing, and stories which lack quality information on the subject. The portrayal influenced by media and the popular discourse is limited and one-sided.

However, media could be powerful in combating the negative perceptions and stigma through the promotion of patient-socialintegration and individual growth and awareness. Since the media does influence people's attitudes, perhaps by showing both the good and the bad, the connection between persons with mental health issues and society will not always be perceived as negative (Marino et al., 2020). For example, when media focus on informative rather than stigma-oriented messages about mental health problems, such as depression and suicide, positive outcomes are related to developing outreach opportunities and assisting with the ability to seek help (Hoffner and Cohen, 2018).

Conversely, this pattern is consistent with evidence that both self-stigma and perceived public stigma can contribute to a reluctance to seek mental health treatment (Henderson et al., 2013). Media campaigns that focus on destigmatizing patients with mental health problems seem to contribute to social integration. These include programs that sensitize populations on the topic, and offer alternative treatments that allow for their social integration (Cuenca, 2003; Crespo et al., 2008; Muñoz et al., 2011). Research (Schiappa et al., 2005; Hoffner and Cohen, 2018) which examined positive portrayals of social group members proposed that such portrayals can lead to more favorable attitudes and behaviors toward that group.

Furthermore, studies have demonstrated that reactions and perceptions are less negative when individuals have personal contact and share experiences with an individual with mental health problems, and that the proximal social exchange with persons who have mental health disorders has a positive effect on their well-being (Clair et al., 2016; Tough et al., 2017). For example, researchers (Pettigrew et al., 2011; Hoffner and Cohen, 2018) examined the effects of positive contact between members of different groups, and they found that this can reduce stereotyping, prejudice, and anxiety about interaction. Even more, contact with individuals of stigmatized groups has proven to be greatly beneficial for stigma reduction (Kosyluk et al., 2016).

Familiarity seems to impact perceptions and play a positive role in reducing social stigmatization and increasing social integration. Utilizing mass media as an alternative mental health 
intervention could be implemented not only to successfully treat patients with mental health problems, but it could also narrow the gap between stigmatized and non-stigmatized groups in terms of stigma reduction and social integration.

\section{BENEFITS OF MENTAL HEALTH ALTERNATIVE INTERVENTIONS}

Regarding treatment of patients with mental health issues, a great deal of research demonstrates significant benefits of using alternative methods of integration into common social activities such as media outlets, art, and traditional and digital games (Silverman, 2006, 2009; Grocke et al., 2009; Lipe et al., 2012; Crone et al., 2013; Hohmann et al., 2017; Mahendran et al., 2017; Dunphy et al., 2019). Patients treated with alternative mental health interventions become more resilient and engage in understanding their condition, which translates into positive outcomes (Brandao et al., 2019; Dunphy et al., 2019). For instance, patients with chronic mental illness benefited from arts intervention experiences, since these provided them with opportunities to relieve stress and develop coping skills (Lipe et al., 2012; Oklan and Henderson, 2014).

Additional research (Hohmann et al., 2017) reviewed the effects of music-based interventions in comparison with traditional psychological therapies. The study showed that music therapy used to treat individuals with substance use disorders provided patients with successful opportunities to emotionally self-express, increase group cooperation and social cohesion, and positively impacted the participants' mood and motivation. Furthermore, research studies (Silverman, 2003) on the impact of music on the symptoms of psychosis found evidence that music therapy successfully helped individuals to manage symptoms. Research (Carras et al., 2018) on the efficacy of games as interventions for reducing mental health problems; where the primary purpose was to educate, train, or change behavior; showed potential benefits in treatment for mental health disorders. A good example is the use of video games as an alternative intervention to treat mental health problems which allows patients to recover from stress, build cooperative connections, and engage in opportunities for entertainment. These correspond with aspects of mental health by possibly promoting a mindfulness-like psychological decentering (Bowman and Tamborini, 2012; Rigby and Ryan, 2017).

Moreover, alternative interventions that involve the wider community could only favor the patients with mental health disorders but could also contribute in bridging the distance between the stigmatized and non-stigmatized members of society. This would thereby increase understanding and consequently de-stigmatize and promote opportunities for patients to seek help when in need. A research study (Faigin and Stein, 2015) examined the impact of community engagement activities where adults with psychiatric disabilities performed for the community. The results demonstrated that integrating theatrical activities positively impacted audience understanding and emotional connections between patients and community, and generated positive emotional growth of the individuals with mental health disorders.

Similar results were exhibited in studies that involved the use of mass media as alternative interventions (Hoffner and Cohen, 2018). For example, in a meta-analysis research study (Pettigrew et al., 2011), intergroup contact demonstrated that emotional outcomes are stronger than cognitive or informative outcomes in intergroup contact, resulting in more associations, empathy, and a reduction of prejudice. Additionally, according to the study, the results were consistent in the utilization of mass media, even though the intergroup contact is indirect. For instance, investigators have repeatedly shown that greater exposure to social targets significantly enhanced positive attitudes toward those targets (Harmon-Jones and Allen, 2001; Pettigrew et al., 2011; Hoffner and Cohen, 2018) even if they were previously unknown (Rhodes et al., 2001).

Stigma is a major obstacle for people living with mental illness. The radio as communication media can act as a therapeutic, educational, and social bridge between hospitalized patients and the "society outside." Through this bridge, patients can feel connected to the larger society, while members of the "society outside" can explore and ideally understand mental health and individuals living with mental health issues. Thus, radio becomes a tool of inclusion, supporting patients, in addition to clinical and social work.

\section{A MODEL OF MEDIA AS ALTERNATIVE HEALTH INTERVENTION FOR SOCIAL INTEGRATION AND HELP SEEKING}

Research by Bilge (2018) affirms that communication is not simply a tool but is the framework or the essential context in which identities are formed, strengthened, and passed along. Studies connecting mass media and stigma for individuals with mental health problems conclude that mass media can play an essential role in the way society perceives mental illness (Tilli, 2016). This can help deconstruct these social representations and offer a process for more "human" co-construction toward social integration.

A groundbreaking initiative, born in Argentina and later implemented in France, uses communications media to provide people with mental illnesses with active roles entailing a social purpose. Les Hauts Parleurs (The Speakers) is a radio station affiliated with a Toulouse, France psychiatric hospital where patients are the on-air hosts. This enables them to establish bridges to the outside world and gives a radically new face to mental illness. Les Hauts Parleurs is one of the "branches" of the Argentinean radio show, "La Colifata" (The Crazy), which began as an underground radio program before being recognized as a valuable public service. The concept has since been copied worldwide.

\section{Les Hauts Parleurs, Toulouse, France}

Radio system Les Hauts Parleurs was inspired by the Argentinian initiative Radio la Colifata. La Colifata is a non-governmental civil organization born in Argentina that is dedicated to the 
development of investigative activities and to offering mental health services utilizing the media with the purpose of providing "spaces of health" to patients with mental health problems. As part of the organization, Alfredo Olivera created the radio program La Colifata which is the first radio in the world to broadcast from within a psychiatric hospital: "El Borda" in Buenos Aires, Argentina. It has been expanding to various parts of the world with the goal of "examining the effectiveness of using media as a platform of self-expression for patients with chronic mental illness" (http://lacolifata.com.ar/en/).

Les Hauts Parleurs radio initiative was born in Toulouse, France and is also part of Alfredo Olivera's goal of creating a space of emancipation for individuals with mental health problems. Using the communication media (radio), the project takes place within the psychiatric institution, more specifically it broadcasts from the hospital's cafeteria. The radio system Les Hauts Parleurs represents an innovative alternative structured around the idea that: (1) the patient is an actor in his/her healing; (2) it is necessary to fight against the stigma of the patient and the disease; (3) mental illness is compatible with life in and with society.

The Les Hauts Parleurs system is open. The presence and participation of family members, friends, listeners, patients from other institutions and visitors is encouraged. The feedback from listeners and people outside the group meeting around the radio is fundamental to working within the group. In addition, the published material is published online and distributed to partner radios to amplify the desired impact. Initially, the radio program is transmitted from the cafeteria of the hospital (a public space open to all). On Monday, every 2 weeks, a recording is made from 2 p.m. to 3 p.m. The program has a telephone line connected to an answering machine in order to receive feedback from listeners.

\section{THE STUDY}

A qualitative design is useful for understanding voices, views and perceptions about phenomena as stigma regarding mental illness: "Qualitative research contributes to an understanding of the human condition in different contexts and of a perceived situation" (Bengtsson, 2016, p. 1). This project employs qualitative methods to explore the accounts of experiences and perceptions of individuals with mental health disorders who are hospitalized at the mental health institution and who took part in the radio program called Les Hauts Parleurs, also included were psychology program master students who participated in the radio program as audience members by attending the program recording at the institution. Data mainly derived from hospitalized patient testimonies and radio programs audience members' testimonies.

We gained access to the data through one of the researchers who is the founder and coordinator of the radio program. Therefore, the researcher constantly interacts with members hospitalized in the mental health institution and coordinates all the aspects of the broadcasting the radio program. The researcher provided us with the recordings of the radio programs which are periodically distributed to the general public by publishing them on the radio Webpage (https://www.nicolastilli.com/radio-experience).

\section{Data Collection}

The study contained testimonies from four (4) radio program shows (11 April, 2019; June 17, 2019; May 9, 2019; on 28 March, 2019) which were open to the public and are periodically published on radio Website. In-patients who participated in the radio programs used for this study had been living in the psychiatry, a public institution in the city of Toulouse, France, from where the radio programs were broadcasted and opened to the general public. During the four (4) radio programs, twentytwo (22) in-patients participated. Their ages ranged from 22 to 70 years old. Some of the patients had been living in the institution for a few years and others temporarily, depending on their pathology. We also collected testimonies from five (5) participants who attended the radio shows as audience. The collected testimonies were from psychology major master students who attended program broadcastings as part of their class project.

The in-patients and interviewees were native French speakers. The testimonies were recorded in French using audio recording devices. Afterwards, the testimonies were transcribed and later translated into Spanish and later into English for the purpose of this research study. According to Bailey (2008), it is recommended that the researcher performs the transcribing. Therefore, one of the researchers who is fluent in French and Spanish transcribed the recordings and translated to Spanish. Afterwards, the other two researchers reviewed translations in Spanish and translated into English, and resolved any arising question through team discussion. In order to ensure anonymity and confidentiality, participant names were replaced by pseudonyms.

\section{Data Analysis}

The analysis of the data focused on in-patient testimonies who participated in the radio show broadcasted from Toulouse, France public psychiatric institution in where they were hospitalized and lived, and on testimonies from five psychology major master students who attended the broadcasting of the programs as audience members at the institution.

A qualitative analysis is useful for understanding voices, experiences, and perspectives about social stigma on mental health. The purpose of this study was to analyze perceptions of the radio program as an alternative mental health intervention for the promotion of social integration and stigma reduction guided by Social Identity Theory in connection with Goffman's (1963) notion of stigma. To this end, researchers employed content analysis as the qualitative methodology. Patton (2002) describes content analysis as "any qualitative data reduction and sense-making effort that takes a volume of qualitative material and attempts to identify core consistencies and meanings" (p. 453). Trustworthiness, transparency, reflexibility, and verification are essential in qualitative research which is guided by informants and insightful interpretations (Dotevall et al., 2018). 
Content analysis allows researchers to build connections between the collected data and the context in which the study was performed. This way, the researcher performs a holistic analysis by attempting to reference data in connection with the context, which is an issue of particular importance for a practitionerscholar (Sutton and Austin, 2015). There are several advantages to using content analysis (Berelson, 1952): (1) it is possible to analyze almost any type of recorded content; (2) it can be adapted to any type of textual content; (3) it focuses on systematic analysis using a set of categories or themes; and (4) it uses explicit and precise techniques that can be easily replicated and verified.

Researchers used an inductive approach to analyze data from testimonies as "inductive reasoning is the process of developing conclusions from collected data by weaving together new information into theories" (Bengtsson, 2016, p. 10). The testimonies from in-patients who participated in broadcasted radio programs served as primary source for content analysis. In addition, testimonies from five on-air radio audience participants were recorded. Both, the radio program recordings were later transcribed verbatim and the protocols were thoroughly anonymized during the transcription process. Later on, both documents were translated into Spanish and English and then these transcriptions were utilized for data analysis.

\section{Data Interpretation}

In this study, content analysis was employed to analyze inpatient testimonies from on-air radio programs to collect perceptions and experiences from those participating in the program. Qualitative data analysis was guided by the steps for conducting data analysis as outlined by Miles and Huberman (1994) which include: (a) organizing data and developing codes, (b) noting researcher's reflections on testimonies, observations and interviews, (c) identifying themes and categories, (d) investigating common and different aspects and developing interpretations of themes, (e) verifying interpretations through member check, peer reviews, and triangulation, and finally, (f) writing the report.

Coding refers to the process "of marking segments of data with symbols, descriptive words, or category names" (Johnson and Christensen, 2014, p. 592) with the intent of assigning units of meaning to the inferential information collected in the study (Miles and Huberman, 1994). After organizing data from testimonies from the four on-air radio programs, memos were created to increase researcher reflexivity, when analyzing data, to keep reflective notes of emerging concepts, themes, and patterns, or of any need for further data collection.

Researchers immersed themselves in the transcripts from inpatients' and on-air radio audience members testimonies and let the themes or categories emerged from raw data. We identified more general emerging themes and search connections between themes (Seidman, 1998). Some themes revealed easily, while other themes were harder to identify as they were latent in the text. Finally, we broke data down into themes that described the content. We re-read the testimonies and reviewed the emerging themes to verify the connections. We kept a record of details related to our observations in a Word document thematic chart, organizing data in themes and sub-themes.
Once the themes fully emerged, we analyzed responses from audience members testimonies searching for cross- case and cross-over information (Miles and Huberman, 1994). We followed same content analysis steps as for in-patient testimonies. As a result, themes and subthemes formed and revealed participants' narratives (Miles and Huberman, 1994). The emerging themes informed the study question. This study examined three aspects of the in-patient and audience member testimonies: (1) social stigma of individuals with mental health problems; (2) media as an alternative intervention for individuals with mental health problems, and (3) alternative interventions for stigma reduction and social integration.

Finally, we examined similarities and differences among them, and compared the data from the themes that emerged. Insights were then recorded in these memos and were compared and contrasted with memos from analysis of audience participants' testimonies. The categories were expected to be mutually exclusive (distinct from each other) and exhaustive. The coding process resulted in three distinct themes from in-patient testimonies, while two of the three themes emerged from testimonies were also identified in audience participants data.

To ensure credibility, "there must be a chain of logic between the decisions made and how the study will be conducted. In order to recapitulate and report the development of the process, the researcher should write memos during this process" (Bengtsson, 2016, p. 10). The three members of our research team, each from different academic backgrounds (communication, medicine, and psychology) analyzed and discussed the transcripts. Memos were recorded next to thematic charts and included notes on emerging concepts and/or patterns found in the data, any need for further information, and connections with findings from data collection and analysis.

Several qualitative reliability procedures were considered (Creswell, 2014). These included member-checking of transcripts, writing memos about emerging themes and subthemes and constantly comparing them (continual assessment of data). This allowed researchers to cross-check developed themes, as recommended by Miles and Huberman (1994).

Following the principles of qualitative content analysis, all findings were compared critically and discussed within our research team. We resolved any disagreements by discussion.

A limitation of this method is that content analysis is mostly used to compare and contrast data, and its interpretation is based on externalized, observable content that might not necessarily represent a behavior or attitude (Berelson, 1952; Carley, 1993; Neuendorf, 2002). In this particular study, triangulation of qualitative data generated during the content analysis of testimonies from in-patients and audience member participants from on-air radio show. Participant checking ensured the trustworthiness of data.

\section{RESULTS}

The study was designed to address the following question: How can mass media as an alternative mental health intervention help reduce stigma and increase social integration? Specifically, 
the study addressed the relationship between media, stigma, and society to advance social integration and stigma reduction. To this end, we separated the data obtained from the inpatients and data obtained from audience members. Inpatient data analysis resulted in three main themes, which all exhibited sub-themes that helped us explore the concepts further. Audience data analysis resulted in two main themes and their sub-themes.

Participants of the study included the testimony of twentytwo (22) in-patients and five (5) audience participants from four (4) radio show programs broadcasted from inside a psychiatric hospital in Toulouse, South of France. Table 1 shows the themes which emerged from in-patient testimonies on the radio Les Hauts Parleurs show which connected with the three different aspects of the study: (1) self-identification, (2) institutionalization, and (3) radio as social integration. Table 2 shows the themes that emerged from audience participants testimonies which embrace the "Radio as stigma reduction and social integration" aspect of the study: (1) self-identification and (2) radio as social integration. Emerging themes for in-patients and audience were connected, intertwined, and complemented each other, as well as provided depth to the covered topic on this article.

As demonstrated in these tables, the emergent themes are multi-dimensional and complex. Each theme exhibits intertwined and multi-faceted concepts, which we explore and explain in the following section.

\section{DISCUSSION}

This study examines the social stigma of individuals with mental health problems, the role of the media in the stigmatization of mental health, and how mental health alternative interventions could embrace and transform the negative effects of institutionalization toward stigma reduction and social integration. The study's main purpose was to address the role of mass media as an alternative mental health intervention in helping stigma reduction and social integration through the exploration of the relationship between media, stigma, and society. The testimonies were collected from the radio shows of Les Hauts Parleurs, broadcast from inside the psychiatric hospital in Toulouse, France. In general, the testimonies from in-patients on the show mostly focused on their feelings about how they self-identified in connection with their perceptions of how the outside world sees them. This also included feelings about their experiences in the institution (hospital), and how their participation on the radio impacted them.

On the other side, testimonies from outside participants of the show (listeners or in-hospital outside audience) discussed independently the themes of self-identification and their experiences from participating in the radio show as audience. Yet, the themes from in-patients and audience testimonies who were interviewed were connected. In this section, we analyze the emerging themes and sub-themes, examine their implications, and discuss their connection to the role of mass media as an alternative mental health intervention in helping stigma reduction and social integration.

\section{Self-Identification}

According to Goffman (1963), the notion of social stigma refers to the disapproval of a person or group of people because they are perceived as holding certain characteristics that do not fulfill social expectations. These social perceptions toward the stigmatized person or group of people create a social distinction or separation between the stigmatized member(s) and the other members of a society. Based on Social Identity Theory presented by Tajel (1978), the social identity of an individual is shaped through group identification, and the identification with a group becomes a source of pride and self-esteem which the individual uses to build a positive selfconcept. This representation increases bonding among the nonstigmatized members and differentiates from the stigmatized individuals through hostile and negative reactions. In order for the non-stigmatized social group to maintain the group's positive self-image and self-identity, in-group non-stigmatized members must be evaluated in a more positive manner (Hawley et al., 2014). Consequently, the members from the stigmatized group are usually assigned a social label. For example, in the case of persons with mental health problems the term "crazy" may be used. The group is isolated, devalued, scorned, and ignored; thus, the members suffer from discrimination and prejudice. Research (Lawler et al., 2000; Heath et al., 2001; Hoffner and Cohen, 2018; Smith et al., 2019) demonstrated that in the case of stigmatization of individuals with mental health problems, group members are portrayed as dangerous, unproductive, and violent. These representations of the stigmatized group members impact individual members' confidence, productivity, and treatment outcomes by increasing their suffering, negatively impacting their self-esteem, and by becoming a barrier to their mental health recovery, physical well-being, and lifespan (Muñoz et al., 2009; Clair et al., 2016). Self-identification perceptions are the most prominent themes that arose from in-patients' testimonies (Table 1). The following three sub-themes were consistently intertwined: (1) negative feelings about themselves, (2) feelings of being different from others in the world, and (3) seeing art as a means to connect to self and to express themselves.

At some point during the radio show, most patients demonstrated the need to explain themselves through reinforcement of negative attributions given by social stigma. In most cases, the in-patient's self-identification is extremely negative. For example, Julien (an in-patient) states: “... what I'm working on right now are my faults and a way to accept them." In-patient Nathalie sees herself as an individual who identifies as part of a diseased group, "We are tired from the disease." Furthermore, two-of the in-patient testimonies revealed how the participants have internalized stigmatization labels. Nathalie expressed that she felt " ... we think we are different from others. There are people who hurt you, who make fun of you. There have always been people who laugh ..." And, Gwen (in-patient) sees herself as a threat to society: "It's hard. There are some who freak out." Not only in-patient testimonies revealed that the participants are fully aware of belonging to a "stigmatized" 
TABLE 1 | Themes emerged from in-patients testimonies on radio program.

\begin{tabular}{|c|c|c|}
\hline Theme I & Theme II & Theme III \\
\hline $\begin{array}{l}\text { Self-identification } \\
\text { Sub-themes: } \\
\text { - Negative feelings } \\
\text { about themselves } \\
\text { - Feeling of being } \\
\text { different from the } \\
\text { world } \\
\text { - Art as a means to } \\
\text { connect to self } \\
\text { and expression }\end{array}$ & $\begin{array}{l}\text { Institutionalization } \\
\text { Sub-themes: } \\
\text { - Isolation } \\
\text { - Depression, anxiety, } \\
\text { and fear } \\
\text { - Institution as enemy }\end{array}$ & $\begin{array}{l}\text { Radio as social } \\
\text { integration } \\
\text { Sub-themes: } \\
\text { - Feeling of the possibility to } \\
\text { share suffering } \\
\text { - Feeling of being } \\
\text { connected to the outside } \\
\text { - Feeling of being "normal" }\end{array}$ \\
\hline
\end{tabular}

TABLE 2 | Themes emerged from audience participants testimonies on radio program.

\begin{tabular}{ll}
\hline Theme I & Theme II \\
\hline Self-identification & Radio as stigma reduction \\
Sub-themes: & Sub-themes: \\
- Feeling of self-connection and & - Means for understanding of the "Other" \\
self-relief & with mental health disorders \\
- Feeling of compassion & - Means of self-understanding and self- \\
and sympathy & reflection \\
& - Means of advancing society \\
\hline
\end{tabular}

group which is different from the "normal" world, this state of awareness seems to generate and be connected to a feeling of vulnerability and hopelessness. For example, Coraly (in-patient) commented during the show about how patients felt, "We are fragile." To this, Julien, an in-patient, added a description of how his emotions were similar to the unstable movement of balloons, which seems to represent how the social labels and expectations affect their [in-patients] state of mind:

Coraly: I had so much pressure when I was told that I must be a normal person that I tend to forget that I am sick and that I have to take care of myself; and I feel I live within balloons [unstable emotions]. And, ... I plunge into depression because I realize that I am not able to keep up with a rhythm that they [society in general] would like me to go. And, then as I have a fear of depression, I stop the drugs and I go into a pothole and that's how I end up in this hospital.

Coraly's testimony addresses Goffman's (1963) discussion on the effects of hospitalization. Goffman (1963) states that the hospitalization of patients with mental health problems might further impact their identity because the patient is socially labeled once hospitalized which could cause further deviation from societal expectations. The internalizing of these labels and deviation might generate in the patient the perception of losing personal power and control, entering in a recurrent circle of marginalization. The use of art as alternative intervention might be effective in alleviating patients' suffering which was another recurrent topic of conversations on the radio show. The topic would arise as a piece of advice among the participants as they tried to help each other find ways to feel better. A great deal of research supports the significant benefits of integrating alternative methods to treat patients (Silverman, 2006, 2009; Grocke et al., 2009; Lipe et al., 2012; Crone et al., 2013; Hohmann et al., 2017; Mahendran et al., 2017). These alternative treatments help patients with mental health disorders become more resilient and engage in understanding their condition, which translates into positive outcomes (Brandao et al., 2019). For example, inpatients would tell stories of how art ameliorated their symptoms and helped them establish a connection to themselves and their ability to express their feelings. In one of the radio shows, Laurent (in-patient) stated that, "When I'm not well I don't know what to do. My body is tired, and I let it rest." In-patient Nathalie responded to this quote by saying, "When I'm not well, I listen to music, I dance, express myself." During a different show, Gwen (in-patient) rapped a song he had written for the radio program. In another show, Monique (in-patient) told her peers that, "I write poems of poetry, that's what I like." Later, she read her poetry on the radio show. When finished reading, she added that, "I write because it is my necessity, insofar as it is precisely my loneliness."

\section{Institutionalization}

Goffman's (1961) description of the traditional structure of mental institutions is compared to prisons, where patients are isolated from the world, radically taken from their usual routine, and subjected to restriction of freedom. Most of the testimonies from in-patients circled around Goffman's description of this traditional view with emphasis on the corrosive effects of "isolation" on in-patients. For example, Julien (in-patient) shares his story on the radio show and says, "... we end up in the hospital like a vegetable; we are forced to be locked up and we don't like it. So, the nurses are our enemies. We tend to believe that suddenly." And, Jose, another in-patient, affirmed Julien's testimony: "We're all going around in circles because we feel locked up When I'm in the hospital, my mom is the only one who comes to visit me. Most of the time, we have nothing to do; so we smoke cigarettes." In another radio show, the same topic arose, and Coria (in-patient) remarked: "I feel little anxiety because I'm alone. I have my partner. But, I actually miss my father, I miss my mother, I miss my sister." These testimonies reinforce Goffman's (1963) analysis on stigma on how hospitalization impacts identity of the mentally ill patients by removing power from the individual through the discrediting from society and perpetuating hopelessness.

The feeling of isolation, which has been reported in almost all the in-patients' testimonies, correlated with two other recurrent sub-themes: (1) feelings of depression and anxiety, and (2) feeling that the institution was their enemy. For example, as in-patient Julien explained to in-patient Nathalie during the radio show: "I was baptized. I made communion. But, sometimes I wonder what I did to become like this. It confuses me. As a result, I don't believe in God anymore." And Coraly, another in-patient, asserted: "They don't care [hospital staff]."

Julien (an in-patient) explained how he was aware of the stigmatization and how the institution has taken away from him all the normal social roles which seems to lead to the loss of his usual identify (Chow and Priebe, 2013): 
Julien: “. . when we are not doing, well we have the impression that these drugs poison us because they [the drugs] modify our metabolism, our saliva, we have rotten teeth, and there are side effects. The first month after I was hospitalized, I went out and I walked like that a zombie."

The testimonies from in-patients connect to Goffman (1961) description of the emotional process the mental health individual experiences before and during hospitalization. Goffman (1961) explains that the suffering person is perceived as losing control and capacity to cope with their lives, and the hospitalized individuals usually go through periods of feeling abandonment and embitterment, punished and trapped due to the losing of their rights.

As part of the new perspectives on deinstitutionalization, research studies (Farnese and Langher, 2010; Novella, 2010; Prins, 2011; Chow and Priebe, 2013) have examined alternative treatments, activities and therapies that may help patients alleviate their suffering and motivate interactive relationships between people with mental problems and the outside community. The research focuses on the benefits of these new approaches as improvement for in-patients, seeking assistance from the general community, and advancement of stigma reduction and social integration through awareness and education.

\section{Media as Alternative Intervention}

Research demonstrated that patients with chronic mental illnesses benefited from alternative intervention experiences because they provided them with opportunities to relieve stress and provide coping skills (Lipe et al., 2012; Oklan and Henderson, 2014). Importance of sharing their suffering was a reoccurring topic of in-patient testimonies. In many ways, in-patients connected their ability to share their experiences to a perception of freedom. As in-patient Pierrette explains, "I came [to the radio program] and it makes me feel good because I feel less lonely. I'd like to read for someone, to help others be less alone." And Robert, another in-patient adds: "I feel good when I am in contact. I love human contact. When I arrive [to the radio program] I feel less alone." On a different radio program, Collette (in-patient) answered the question about why she participated in the radio show by saying: "I come to not be alone." Gwen (an in-patient) added: "I can express myself and somebody hears."

In-patients see the opportunity of participating on the radio as a catalyst for sharing their suffering and this somehow generates a connection with the outside world, resulting in alleviation of negative emotions. Gwen, an in-patient, expressed that the opportunity to participate in the radio program represents connection to reality, others, and himself: "I can thank my loved ones;" "I can connect to outside;" "We're back to reality;" "I feel good when I am in contact. I love human contact."

Repeatedly, research demonstrated the positive outcomes of using mass media as an alternative intervention, resulting in a reduction of prejudice (Pettigrew et al., 2011; Hoffner and Cohen, 2018). In addition, investigators have shown that greater exposure to social targets significantly enhanced liking and empathy for those targets (Harmon-Jones and Allen, 2001;
Pettigrew et al., 2011; Hoffner and Cohen, 2018) even if they were previously unknown (Rhodes et al., 2001).

This radio initiative seeks to create virtual bridges that bring together two artificially separated sectors of society and, in this way, to influence their identifications. The main goal was built around the beneficial effects of the establishment of a different relationship between the stigmatized group (individuals with mental health disorders) and the non-stigmatized society. This goal represented the establishment of a basis for social integration. Indeed, communication through this radio program presents itself as the means by which subjects construct and transform their world and positively impact the outside world. Speaking through this communication medium can therefore mean the possibility to "re-entry" or integrate into the social body.

Regarding this impact on individuals who are not identified as members of a stigmatized group, here are some examples of testimonies from listeners (the audience). Having listened to the broadcast program, these (in-patient) participants reflected on the experience of sharing with individuals who had mental health disorders. For example, a male called Alexander stated that he comes to the radio because "I can speak and express freely." Laurent, another female patient, reasserts Alexander's statement and adds that "I like the radio because I feel pleasure meeting others and meeting the outsiders." Likewise, a male patient called Guillaume addresses the fact that the radio is a space to share his suffering with the goal of finding sympathy from the wider community and to help people understand his suffering. $\mathrm{He}$ states: “... being here is the reason of my trauma. I hope people will understand my point of view and accept it."

In-patient Ludovic calls to the community and his peers to participate in the radio show because he feels it is important to be heard: "come and talk with us about essential topics. You may have something important to say. You may be missing the opportunity to be heard by somebody."

The experiences explained by Philippe (audience) reflect how their interactions with the radio system allow them (the audience/outsiders) to transform their perspectives about mental health disorders and individuals with mental health issues.

Philippe (outside listener/audience): This is my second attendance and it makes me feel good; because, I love radio and it feels very good to come and listen to different opinions.

I listen attentively the life stories here [mental health institution], actually we talk a lot about life outside. There is a life outside so I listen to stories and I tell myself that there is a life also here. It makes you reflect.

In addition, Cristina, who is a mental health student fulfilling an internship in the hospital and participates in the radio show as an audience member (from within the hospital), declares that participation in the radio program facilitates means for advancing the society. She expresses her perceptions for a need to widen the audience for the radio program:

Cristina (outside listener/audience): It would be great if others in the community were willing to participate. It would be fabulous. 
Nobody will be judged. We are here to understand each other, share, and talk.

Another audience member and psychology intern and student, Nathalie, says, "With words we can explain the disease and we can bring people to light."

Moreover, alternative interventions, such as this radio program, could be means of self-understanding and selfreflection. Research (Faigin and Stein, 2015) shows that alternative interventions, which involve the wider community, could contribute in narrowing the distance between the stigmatized and non-stigmatized members of the society by increasing understanding of mental health problems. This understanding could also promote audience help-seeking as well as the positive emotional growth.

The following three testimonies from audience members who participated in the radio shows revealed how the radio program served to help with de-stigmatization of mental health problems, giving the general community a tool for self-understanding and help seeking. For example, after listening to the testimonies of inpatients, audience member and psychology student Philippe said: "Now I realize that I need help and that it is ok." And, testimonies seemed to also impact audience member Tanguy with emotional understanding. He said, "I would like to help someone and be helped too...."

Through the radio program as means of communication, the hospital can open up toward society and society can respond to the hospital patients. This would alleviate the stigmatizing and discriminatory presumptions from outside to inside (toward the "suffering person" and "mental illness"). The patients can free their voice and make a social link with the outside. The connection with the outside world produces new knowledge that is less stigmatizing and discriminatory as well as creating a positive mental health alternative treatment for in-patients as means of expression.

\section{CONCLUSION}

Communication, including use of media, has a crucial role in extending the prejudices and stereotypes historically associated with mental health problems, ultimately building social stigma (Smith, 2011; Smith et al., 2019). Stigma is constituted by negative attitudes which are based on erroneous generalizations toward a group or its members. Goffman's (1963) work teaches us that people are stigmatized when social expectations of them are greater than they actually present. This expectation is based on a judgment of social value, on what individual social identity should be.

Social stigma affects individuals with mental health problems by increasing their suffering, and is detrimental to their selfesteem, mental health recovery, physical well-being, and lifespan
(Muñoz et al., 2009; Clair et al., 2016). Furthermore, not only is the quality of life of the individuals and their families negatively impacted because they experience rejection and discrimination, but the social infrastructure is also affected because mental health problems are socially discredited. This results in poor service, inadequate funding and treatment, consequently hindering progress toward recovery from mental illness (Markowitz, 2001; Pescosolido et al., 2008; Pescosolido and Martin, 2015).

The building blocks of the stigma reveal the importance of the "Other" or "others" in its constitutive process where communication and media are of great importance in perpetuating or decreasing social stigma. The term deinstitutionalization is an evolving concept (Chow and Priebe, 2013). Part of the debate has been addressing the need for the incorporation of alternative treatments that connects the patients to the outside world and builds relationship with the community. The ultimate goal is promoting stigma reduction, social awareness, and social integration (Muñoz et al., 2009; Hawley et al., 2014; Clair et al., 2016). The establishment of virtual bridges through alternative interventions might allow the meeting of stigmatized individuals with the rest of society with the objective of deconstructing and co-constructing the perceptions of mental health disorders. Consequently, this radiophonic device, as a therapeutic bond, could increase social integration and decrease stigmatization by favoring a different encounter between the person with mental health problems and the society. That is to say, an encounter that brings awareness and knowledge which could open the possibility for an individual with mental health issues to leave the stigmatizing circuit. And, it might aid society in increasing understanding, acceptance, and awareness.

\section{DATA AVAILABILITY STATEMENT}

The raw data supporting the conclusions of this article will be made available by the authors, without undue reservation.

\section{ETHICS STATEMENT}

Ethical review and approval was not required for the study on human participants in accordance with the local legislation and institutional requirements. Written informed consent for participation was not required for this study in accordance with the national legislation and the institutional requirements.

\section{AUTHOR CONTRIBUTIONS}

MM researched, analyzed, and wrote the article. OA transcribed, helped, analyzed, and helped with editing and revision of article. NT collected the data. All authors contributed to the article and approved the submitted version.

\section{REFERENCES}

Bailey, J. (2008). First steps in qualitative data analysis: transcribing. Fam. Prac. 25, 127-131. doi: 10.1093/fampra/cmn003

Bengtsson, M. (2016). How to plan and perform a qualitative study using content analysis. NursingPlus Open 2, 8-14. doi: 10.1016/j.npls.2016.01.001

Berelson, B. (1952). Content Analysis in Communication Research. New York, NY: Free Press. 
Bilge, N. (2018). Refugee Identities: Ethnicity as a communicative process. J. Intercult. Commun. Res. 47, 226-242. doi: 10.1080/17475759.2018.1455602

Bowman, N. D., and Tamborini, R. (2012). Task demand and mood repair: the intervention potential of computer games. N. Media Soc. 14, 1339-1357. doi: $10.1177 / 1461444812450426$

Brandao, F. M. V., Silva, C. V., Silva Goncalves de Oliveira, K. R., and Silva Pedroso, J. (2019). Art as a therapeutic tool in depressive disorders: a systematic review of the literature. Psychiatr. Quart. 4:871. doi: 10.1007/s11126-019-09672-x

Carley, K. (1993). Coding choices for textual analysis: a comparison of content analysis and map analysis. Sociol. Methodol. 23, 75-126. doi: 10.2307/271007

Carras, M. C., Kalbarczyk, A., Wells, K., Banks, J., Kowert, R., Gillespie, C., et al. (2018). Connection, meaning, and distraction: a qualitative study of video game play and mental health recovery in veterans treated for mental and/or behavioral health problems. Soc. Sci. Med. 216, 124-132. doi: $10.1016 /$ j.socscimed.2018.08.044

Chen, G. M. (2012). The impact of new media on intercultural communication in global context. China Media Res. 8, 1-10. Available online at: http://www. wwdw.chinamediaresearch.net/index.php/back-issues?id=54

Chernomas, W. M., Clarke, D. E., and Chisholm, F. A. (2000). Perspectives of women living with schizophrenia. Psychiatr. Serv. 51, 1517-1521. doi: $10.1176 /$ appi.ps.51.12.1517

Chow, W. S., and Priebe, S. (2013). Understanding psychiatric institutionalization: a conceptual review. BMC Psychiatry 13, 1-14. doi: 10.1186/1471-244X13-169

Clair, M., Daniel, C., and Lamont, M. (2016). Destigmatization and health: cultural constructions and the long-term reduction of stigma. Soc. Sci. Med. 165, 223-232. doi: 10.1016/j.socscimed.2016.03.021

Corrigan, P. W., Watson, A. C., Warpinski, A. C., and Gracia, G. (2004). Stigmatizing attitudes about mental illness and allocation of resources to mental health services. Commun. Mental Health J. 40, 297-307. doi: 10.1023/B:COMH.0000035226.19939.76

Coverdale, J., Nairn, R., and Claasen, D. (2002). Depictions of mental illness in print media: a prospective national sample. Aust. N. Zeal. J. Psychiatry 36, 697-700. doi: 10.1046/j.1440-1614.2002.00998.x

Crespo, M., Muñoz, M., Pérez Santos, E., and Guillén, A. I. (2008). Stigma associated with severe and persistent mental illness among the general population of Madrid (Spain): descriptive study. Commun. Mental Health J. 44, 393-403. doi: 10.1007/s10597-008-9142-y

Creswell, J. (2014). Research Design, 4th Edn. Thousand Oaks, CA: Sage.

Crone, D. M., O'Connell, E. E., Tyson, P. J., Clark, S. F., Opher, S., and James, D. V. B. (2013). "Art Lift" intervention to improve mental well-being: an observational study from UK general practice. Int. J. Mental Health Nurs. 22, 279-286. doi: 10.1111/j.1447-0349.2012.00862.x

Cuenca, O. (2003). El estigma de la enfermedad mental en los medios de comunicación. Retos para la Psiquiatría y la Salud Mental en España, 309-320.

Cutcliffe, J. R., and Hannigan, B. (2001). Mass Media, "monsters" and mental health clients: the need for increased lobbying. J. Psychiatr. Mental Health Nurs. 8, 315-321. doi: 10.1046/j.1365-2850.2001.00394.x

Dotevall, C., Winberg, E., and Rosengren, K. (2018). Nursing students' experiences with refugees with mental health problems in Jordan: a qualittive content analysis. Nurse Educ. Today 61, 155-161. doi: 10.1016/j.nedt.2017. 11.025

Dunphy, K., Baker, F. A., Dumaresq, E., Carroll-Haskins, K., Eickholt, J., Ercole, M., et al. (2019). Creative arts interventions to address depression in older adults: a systematic review of outcomes, processes, and mechanisms. Front. Psychol. 9:2655. doi: 10.3389/fpsyg.2018.02655

Faigin, D. A., and Stein, C. H. (2015). Community-based theater and adults with psychiatric disabilities: social activism, performance and community engagement. Am. J. Commun. Psychol. 55, 148-163. doi: 10.1007/s10464-014-9695-6

Farnese, A., and Langher, V. (2010). The de-institutionalization of psychiatric patients through. psycho-social rehabilitation. J. Spec. Educ. Rehabil. $1-2,87-102$

Goffman, E. (1961). Asylums; Essays on the Social Situation of Mental Patients and Other Inmates. Garden City: Anchor Books.

Goffman, E. (1963). Stigma: Notes on the Management of Spoiled Identity. New York, NY: Simon and Schuster.
Gorodzeisky, A., and Semyonov, M. (2017). Labor force participation, unemployment and occupational attainment among immigrants in West European countries. PLoS ONE 12:e176856. doi: 10.1371/journal.pone. 0176856

Grocke, D., Bloch, S., and Castle, D. (2009). The effect of group music therapy on quality of life for participants living with a severe and enduring mental illness. J. Music Ther. 46, 90-104. doi: 10.1093/jmt/46.2.90

Hall, E. T. (1976). Beyond Culture. Garden City, NY: Doubleday Anchor.

Harmon-Jones, E., and Allen, J. J. B. (2001). The role of affect in the mere exposure effect: Evidence from physiological and individual differences approaches. Pers. Soc. Psychol. Bull. 27, 889-898. doi: 10.1177/0146167201277011

Hawley, L. R., Hosch, H. M., and Bovaird, J. A. (2014). Exploring social identity theory and the "black sheep effect" among college student-athletes and nonathletes. J. Sport Behav. 37, 56-76.

Heath, C., Bell, C., and Sternberg, E. (2001). Emotional selections in memes: the case of urban legends. J. Pers. Soc. Psychol. 81, 1028-1041. doi: 10.1037/0022-3514.81.6.1028

Henderson, C., Evans-Lacko, S., and Thornicroft, G. (2013). Mental illness stigma, help seeking, and public health programs. Am. J. Public Health. 103, 777-780. doi: 10.2105/AJPH.2012.301056

Hinshaw, S. P., and Cicchetti, D. (2000). Stigma and mental disorder: conceptions of illness, public attitudes, personal disclosure and social policy. Dev. Psychopathol. 12, 555-598. doi: 10.1017/S0954579400004028

Hoffner, C. A., and Cohen, E. L. (2018). Mental health-related outcomes of robin williams' death: the role of parasocial relations and media exposure in stigma, help-seeking, and outreach. Health Commun. 33, 1573-1582. doi: $10.1080 / 10410236.2017 .1384348$

Hogg, M., and Terry, D. (2000). Social identity and self-categorization processes in organizational contexts. Acad. Manag. Rev. 25, 121-140. doi: $10.5465 / \mathrm{amr} .2000 .2791606$

Hohmann, L., Bradt, J., Stegemann, T., and Koelsch, S. (2017). Effects of music therapy and music-based interventions in the treatment of substance use disorders: a systematic review. PLoS ONE 12:e0187363. doi: 10.1371/journal.pone. 0187363

Huang, B., and Priebe, S. (2003). Media coverage of mental health care in UK, USA and Australia. Psychiatr. Bull. 27, 331-333. doi: 10.1017/S0955603600002968

Jaldemark, J. (2008). Participation and genres of communication in online settings of higher education. Educ. Inform. Technol. 13, 129-146. doi: 10.1007/s10639-008-9057-9

Johnson, R., and Christensen, L. (2014). Educational Research: Quantitative, Qualitative, Andmixed Methods. 5th Edn. Thousand Oaks, CA: Sage.

Knutson, T., Komolsevin, R., Chatiketu, P., and Smith, V. (2003). A cross-cultural comparison of Thai and US American rhetorical sensitivity: implications for intercultural communication effectiveness. Int. J. Int. Relat. 27, 63-78. doi: 10.1016/S0147-1767(02)00060-3

Kosyluk, K. A., Al-Khouja, M., Bink, A., Buchholz, B., Ellefson, S., Fokuo, K., et al. (2016). Challenging the stigma of mental illness among college students. J. Adol. Health 59:325. doi: 10.1016/j.jadohealth.2016.05.005

Kreijns, K., Kirschner, P., and Jochems, W. (2003). Identifying the pitfalls for social interaction in computer-supported collaborative learning environments: a review of the research. Comput. Hum. Behav. 19, 335-353. doi: 10.1016/S0747-5632(02)00057-2

Lawler, E. J., Thye, S. R., and Yoon, J. (2000). Emotion and group cohesion in productive exchange. Am. J. Sociol. 106, 616-657. doi: 10.1086/318965

Link, B. G., and Phelan, J. C. (2006). Stigma and its public health implications. Lancet 367, 528-529. doi: 10.1016/S0140-6736(06)68184-1

Lipe, A. W., Ward, K. C., Watson, A. T., Manley, K., Keen, R., Kelly, J., et al. (2012). The effects of an arts intervention program in a community mental health setting: a collaborative approach. Arts Psychother. 39, 25-30. doi: $10.1016 /$ j.aip.2011.11.002

Lowstedt, A., and Mboti, N. (2017). Media racism: beyond modernity and postmodernity. Int. J. Media Cult. Polit. 13, 111-130. doi: 10.1386/macp.13.1-2.111_1

Mahendran, R., Rawtaer, I., Fam, J., Wong, J., Kumar, A. P., Gandhi, M., et al. (2017). Art therapy and music reminiscence activity in the prevention of cognitive decline: study protocol for a randomized controlled trial. Trials 1:1. doi: 10.1186/s13063-017-2080-7 
Marino, M. I., Bilge, N., Gutsche, R. E., and Holt, L. (2020). Who is credible (and where)? using virtual reality to examine credibility and bias of perceived race/ethnicity in urban/suburban environments. Howard J. Commun. 31, 297315. doi: 10.1080/10646175.2020.1714514

Markowitz, F. E. (2001). Modeling processes in recovery from mental illness: Relationships between symptoms, life satisfaction, and self-concept. J. Health Soc. Behav. 42, 64-79. doi: 10.2307/3090227

Miles, M., and Huberman, A. (1994). Qualitative Data Analysis: A Sourcebook of New Methods 2nd Edn. Thousand Oaks, CA: Sage.

Muñoz, M., Pérez-Santos, E., Crespo, M., and Guillén, A. I. (2009). El Estigma de la Enfermedad Mental. Madrid: Ed. Complutense.

Muñoz, M., Pérez-Santos, E., Crespo, M., Guillén, A. I., and Izquierdo, S. (2011). La enfermedad mental en los medios de comunicación: un estudio empírico en prensa escrita, radio y televisión / mental illness in the media: an empirical study in press, radio and television. Clínica y Salud 22, 157-173. doi: $10.5093 / \mathrm{cl} 2011 \mathrm{v} 22 \mathrm{n} 2 \mathrm{a} 5$

Neuendorf, K. A. (2002). The Content Analysis Guidebook. Thousand Oaks, CA: Sage.

Novella, E. J. (2010). Mental health care and the politics of inclusion: a social systems account of psychiatric deinstitutionalization. Theor. Med. Bioeth. 31, 411-427. doi: 10.1007/s11017-010-9155-8

Oklan, A. M., and Henderson, S. J. (2014). Treating inhalant abuse in adolescence: a recorded music expressive arts intervention. Psychomusicol. Music Mind Brain 24, 231-237. doi: 10.1037/pmu0000058

Patton, M. Q. (2002). Qualitative Research and Evaluation Methods. Thousand Oaks, CA: Sage.

Pescosolido, B. A., and Martin, J. K. (2015). “The Stigma Complex." Ann. Rev. Sociol. 41, 87-116. doi: 10.1146/annurev-soc-071312-145702

Pescosolido, B. A., Martin, J. K., Lang, A., and Olafsdottir, S. (2008). Rethinking theoretical approaches to stigma: a framework integrating normative influences on stigma (FINIS). Soc. Sci. Med. 67, 431-440. doi: 10.1016/j.socscimed.2008.03.018

Pettigrew, T. F., Tropp, L. R., Wagner, U., and Christ, O. (2011). Recent advances in intergroup contact theory. Int. J. Intercult. Relat. 35, 271-280. doi: 10.1016/j.ijintrel.2011.03.001

Prins, S. J. (2011). Does transinstitutionalization explain the overrepresentation of people with serious mental illnesses in the criminal justice system? Commun. Mental Health J. 47, 716-722. doi: 10.1007/s10597-011-9420-y

Rhodes, G., Halberstadt, J., and Brajkovich, G. (2001). Generalization of mere exposure effects to averaged composite faces. Soc. Cogn. 19, 57-70. doi: $10.1521 /$ soco.19.1.57.18961

Rigby, C. S., and Ryan, R. M. (2017). “Time well-spent? Motivation for entertainment media and its eudaimonic aspects through the lens of selfdetermination theory," in The Routledge Handbook of Media Use and WellBeing: International Perspectives on Theory and Research on Positive Media Effects, eds L. Reinecke and M. B. Oliver (Routledge; Taylor and Francis Group), 34-48.

Rimal, R. N., and Lapinski, M. K. (2015). A re-explication of social norms, ten years later. Commun. Theory 25:393. doi: 10.1111/comt.12080

Samovar, L., Porter, R., McDaniel, E., and Roy, C. (2010). Communication Between Cultures. Boston, MA: Wadsworth.

Schiappa, E., Gregg, P. B., and Hewes, D. E. (2005). The parasocial contact hypothesis. Commun. Monogr. 72, 92-115. doi: 10.1080/0363775052000342544

Seidman, I. (1998). Interviewing as Qualitative Research: A Guide for Researchers in Education and the Social Sciences, 2nd Edn. New York, NY: Teachers College Press.

Shinnar, R. S. (2008). Coping with negative social identity: the case of Mexican immigrants. J. Soc. Psychol. 148, 553-576. doi: 10.3200/SOCP.148.5.553-576
Silverman, J. J. (2009). The effect of single session psychoeducational music therapy on verbalizations and perceptions in psychiatric patients. J. Music Ther. 46, 105-113. doi: 10.1093/jmt/46.2.105

Silverman, M. J. (2003). The influence of music on the symptoms of psychosis: a meta-analysis. J. Music Ther. 40, 27-40. doi: 10.1093/jmt/40.1.27

Silverman, M. J. (2006). Psychiatric patients' perception of music therapy and other psychoeducational programming. J. Music Ther. 43, 111-122. doi: $10.1093 /$ jmt/43.2.111

Smith, R. A. (2007). Language of the lost: an explication of stigma communication. Commun. Theory 17, 462-485. doi: 10.1111/j.1468-2885.2007.00307.x

Smith, R. A. (2011). "Stigma communication and health," in Handbook of Health Communication, 2nd Edn, eds T. L. Thompson, R. Parrott, and J. Nussbaum (New York, NY: Taylor andFrancis), 455-468.

Smith, R. A., Zhu, X., and Fink, E. L. (2019). Understanding the effects of stigma messages: danger appraisal and message judgments. Health Commun. 34, 424-436. doi: 10.1080/10410236.2017.1405487

Sui, M., and Paul, N. (2017). Latino portrayals in local news media: underrepresentation, negative stereotypes, and institutional predictors of coverage. J. Int. Commun. Res. 46, 273-294. doi: 10.1080/17475759.2017.1322124

Sutton, J., and Austin, Z. (2015). Qualitative research: data collection, analysis, and management. Can. J. Hosp. Pharm. 68, 226-231. doi: 10.4212/cjhp.v68i3.1456

Tajfel, H. (1978). "Social categorization, social identity and social comparison," in Differentiation Between Social Groups: Studies in the Social Psychology of Intergroup Relations, ed H. Tajfel (London: Academic Press), 61-76.

Tajfel, H. (1982). Social psychology of intergroup relations. Annu. Rev. Psychol. $33,1-39$.

Tajfel, H., and Turner, J. C. (1986). The social identity theory of intergroup behavior. In Psychology of Intergroup Relations, eds S. Worchel and W. Austin (Chicago, IL: Nelson Hall), 7-24.

Tajfel, H., Turner, J. C., Austin, W. G., and Worchel, S. (1979). An integrative theory of intergroup conflict. Organ. Ident. 56:65.

Tilli, N. (2016). Les médias de communication audiovisuelle au service de la santé mentale. Communication 33. doi: 10.4000/communication. 5783

Tough, H., Siegrist, J., and Fekete, C. (2017). Social relationships, mental health and wellbeing in physical disability: a systematic review. BMC Public Health 17:414. doi: 10.1186/s12889-017-4308-6

Weaver, C. N. (2007). The effects of contact on the prejudice between Hispanics and non- Hispanic Whites in the United States. Hispanic J. Behav. Sci. 29, 254-274. doi: 10.1177/0739986306296590

Yang, D., Olesova, L., and Richardson, J. (2010). Impact of cultural differences on students' participation, communication, and learning in an online environment. J. Educ. Comput. Res. 43, 165-182. doi: 10.2190/EC. 43.2.b

Zebrowitz, L. A., Bronstad, P. M., and Lee, H. K. (2007). The contribution of face familiarity to ingroup favoritism and stereotyping. Soc. Cogn. 25, 306-338. doi: $10.1521 /$ soco.2007.25.2.306

Conflict of Interest: The authors declare that the research was conducted in the absence of any commercial or financial relationships that could be construed as a potential conflict of interest.

Copyright (C) 2020 Marino, Adogba and Tilli. This is an open-access article distributed under the terms of the Creative Commons Attribution License (CC BY). The use, distribution or reproduction in other forums is permitted, provided the original author(s) and the copyright owner(s) are credited and that the original publication in this journal is cited, in accordance with accepted academic practice. No use, distribution or reproduction is permitted which does not comply with these terms. 